Nacido en Temuco, la tierra jukenil de Neruda, es profesionalmente médico y ejerce en Biclefeld (Alemania). Sus aficiones son Neruda, la literatura, la música y la novela policíaca, con especial interés por las de Conan Doyle y su personaje Sherlock Holmes, cuyos métodos secunda aquí para establecer una atrevida y apasionante deducción.

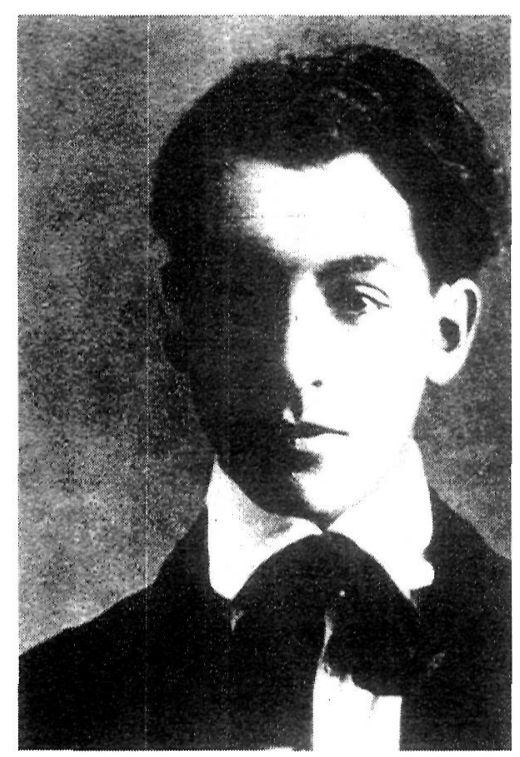

FIG. 1. Neruda en el tiempo juvenil de Temuco.

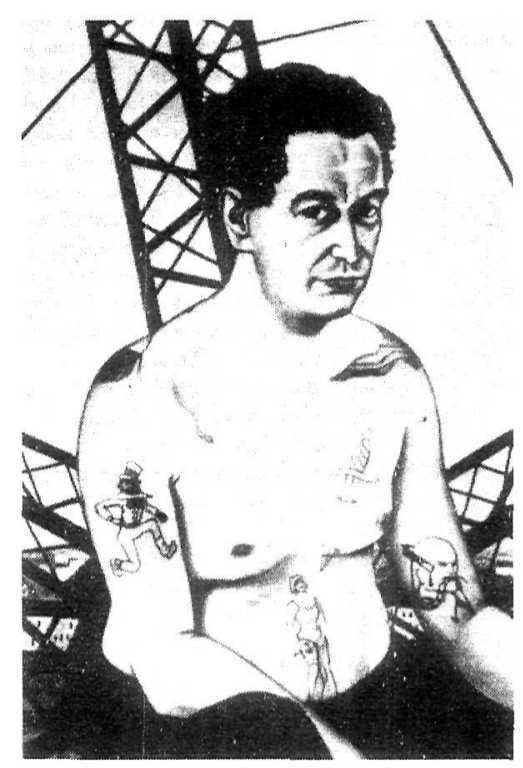

FIG. 2. El periodista checo Egon Erwin Kisch.

Pablo Neruda, el enigma inaugural ENRIQUE ROBERTSON ÁLVAREZ

\title{
PABLO NERUDA, EL ENIGMA INAUGURAL
}

\author{
ENRIQUE ROBERTSON ÁLVAREZ
}

Señor presidente de la sesión, señoras y señores... quiero ante todo, agradecer al Prof. José Carlos Rovira -y a todos los integrantes del comité organizador de este Coloquio- por darme la gran satisfacción de participar en él, junto a nerudistas de tanto y tan merecido renombre. Esto hace aún más grande mi satisfacción pero también me obliga a asumir con cierta preocupación, la nada fácil tarea de tratar de que mi intervención quede a la altura de las circunstancias, y no les aburra o defraude demasiado. Aunque resido en Alemania, he venido con el pretexto de ser de Temuco y ex-alumno del Liceo de esa ciudad del sur de Chile. Y de haber sido allí alumno del profesor Hernán Loyola, aquí presente, cuya amistosa y entusiasta mediación logró para mí la amable invitación del profesor Rovira, que vuelvo a agradecer. El nerudiano tema que he osado intrusear - acerca del cual creo poder dar a conocer aquí un hallazgo novedoso- es el del enigmático origen del nombre Pablo Neruda, sonoro nombre electivo que el vate se dio cuando aún era alumno del Liceo de Temuco. (Fig. 1). Con ese nombre se inauguró como poeta. Transcurría el año 1920 y el estudiante temuquense contaba entonces con escasos 16 años de edad.

No dudo que todos los aquí presentes saben que el poeta sustituyó por Pablo Neruda su nombre pro- pio, que era el de Neftalí Reyes Basoalto. Ricardo Eliecer Neftalí Reyes Basoalto. Muchos años después él mismo se preguntará: «¿Hay algo más tonto en la vida, que llamarse Pablo Neruda?». En relación a ese nombre, nada de tonto y de tan justo retumbo, es otra la pregunta que otros se han hecho más de una vez: ¿cómo se le ocurrió a Neftalí Reyes nombrarse, con tanto acierto, Pablo Neruda? En lo que me toca, declaro que debo a mi profesor de castellano - ya saben ustedes a quién me refiero- el haberme contagiado - hace unos cuarenta años, en Temuco- la manía de hacerme también esa pregunta. Él sabe que en aquellos años elaboré una absurda teoría respecto al origen del nombre Neruda que no logró convencer a nadie. No me referiré a ella porque asesadamente la deseché; aunque pensándolo bien, tan mala no era. Dicho esto y para no alargar más la entrada en materia, me atreveré a comenzar sosteniendo que no se puede hablar de investigar el origen del nombre Pablo Neruda, sin decir que fue Egon Erwin Kisch -escritor y periodista checo al que vemos en este curioso retrato (Fig. 2) quien por primera vez, a mediados del año 1937, preguntó al poeta por qué había elegido ese, precisamente ese nombre. Neftalí Reyes había vivido poético-literariamente hasta los 33 años de edad llamándose Pablo Neruda -y «llenando ese nombre de existencia» como bien dice Loyola- sin que nadie hasta ese momento le hubiese pedido que explicara el porqué de su nombre electivo. Hasta que Kisch llegó a Madrid. A la imprevista pregunta del periodista checo, Neruda no quiso o no pudo dar una respuesta clara. Desde entonces Kisch se la repitió 
una y otra vez, muchas veces; durante toda una década. Egon Erwin Kisch hizo amistad con Neruda en el círculo internacional de amigos y colaboradores de El Mono Azul, publicación semanal de la Alianza de Intelectuales Antifascistas cuyo primer número apareció en Madrid en septiembre de 1936, es decir escasos dos meses después de iniciada la guerra civil. No pocos intelectuales hispanoamericanos colaboraron en El Mono Azul Entre los chilenos, además de Neruda, los más activos eran el músico Acario Cotapos y los poetas Vicente Huidobro y Juvencio Valle. Permítaseme recordar aquí que este último, que fue condiscípulo de Neruda en el Liceo de Temuco, falleció en Santiago de Chile hace pocas semanas, a los 98 años de edad...

El chileno que tuvo el papel más protagónico en El Mono Azul fue sin duda alguna Pablo Neruda (Fig. 3); esta fotografía es una de las tantas pruebas de ello. Su participación en las actividades de la Alianza, considerada impropia de un neutral funcionario consular, sería el motivo por el que se le destituiría de su cargo. Antes de que esto ocurriera, su poema "Canto a las madres de los milicianos muertos" publicado en el número 5 -del jueves 24 de septiembre de 1936- apareció con la nota siguiente: «este poema se debe a la pluma de un gran poeta cuyo nombre la redacción de El Mono Azul estima oportuno no dar por el momento». El nombre de Neruda reaparecería largos meses después, el primero

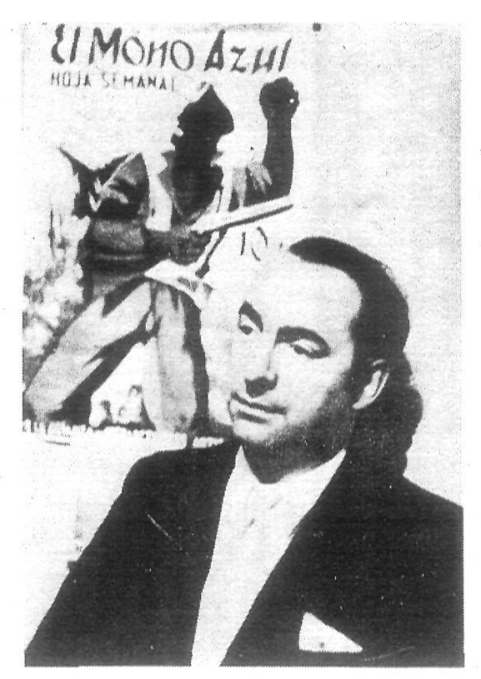

FIG. 3. Pablo Neruda en El mono azul, durante la guerra civil española. de julio de 1937 con su poema "Es así” que después se llamaría "Explico algunas cosas”, tal vez el más importante de los que integran su libro España en el Corazón. Dos semanas más tarde el semanario publicó otra fotografía de Neruda en su portada. Es probable que haya sido alrededor de estas fechas cuando Egon Kisch le preguntó al poeta cómo y por qué se le había ocurrido rebautizarse Neruda. Porque, como vemos (Fig. 4), El Mono Azul del 15 de julio de 1937 muestra en su portada sendas fotografías del checo Kisch y del chileno con nombre checo, Neruda. Es probable que inicialmente Kisch se interesara por saber la proveniencia del apellido del poeta chileno, en el convencimiento de estar hablando con el hijo o nieto de un checo emigrado desde la maravillosa Praga —o de otro lugar de Bohemia - al sur más sur de la América del Sur. Y que por eso cuando este intruso profesional, que siempre quería estar bien informado de todo, oyó decir a Neruda que entre sus antepasados no contaba con ningún checo de ese ni de otro nombre, se sorprendiera muchísimo y quisiera satisfacer su curiosidad preguntándole pero entonces, ¿nombróse usted Neruda..., por Jan Neruda? Comprensible pregunta -que sugería la respuesta- si se sabe que Kisch nació en Praga donde hay una calle $y$ un monumento en memoria y honor al escritor Jan Neruda también nacido allí (Fig. 5).

La obra más conocida de Jan Neruda es su libro Cuentos de Malà Strana, muy admirado por Kisch que en su juventud también escribió unos relatos parecidos a los cuentos de «su» Neruda. Hay indicios, anecdóticos pero muy dignos de crédito, que hacen suponer que antes de conocer a Kisch nuestro Neruda nunca había oído hablar del Neruda checo. De acuerdo con esto último se puede asegurar que recién cuando Kisch le habló de él, el poeta chileno se vino a enterar de que en Praga había existido un escritor de ese nombre. Además - puesto que consideraba a Kisch un
Pablo Neruda, el enigma inaugural ENRIQUE ROBERTSON ÁLVAREZ 


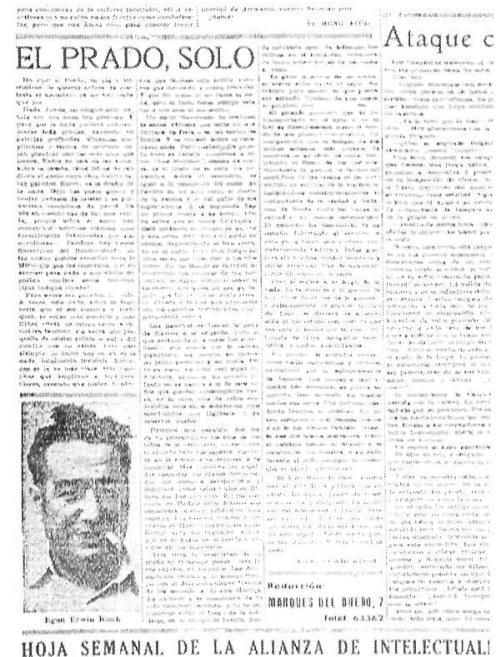

Fig. 6. Artículo de Kisch en El mono azul. gran humorista- debe haber creído que éste bromeaba al relacionarlo con un escritor checo que le era totalmente desconocido. Por eso le contestó en broma desafiándole a que intentase dar él mismo con la respuesta verdadera (a la manera del: «Me preguntáis...?». «Indagadlo, indagadlo» de Los Enigmas); diciéndole además que dudaba de que fuese capaz de resolver el misterio de su nombre con igual éxito que el que había tenido en otros casos. Porque Kisch, que tenía fama de ser una especie de Sherlock Holmes del periodismo, aplicando unos originales e infalibles métodos, había logrado desentrañar más de un caso extraño y misterioso. Neruda cita en sus memorias el del coronel Redl, espía austríaco desenmascarado en 1913 por Kisch, caso con el que el rasante reportero logró ganar gran popularidad. Bohemia y su capital Praga eran entonces parte del Imperio Austro-Húngaro. Egon Kisch pertenecía a la minoría germanoparlante de Praga, donde se inició en el periodismo. Después trabajó diez años en Berlín, colaborando en publicaciones en idioma alemán que se leían también en Praga y en Viena, ciudad esta última donde el escandaloso caso Redl —que Kisch descubrió con la ayuda de un amigo suyo llamado Wagner- tuvo gravísimas repercusiones que contribuyeron no poco al inicio de la primera guerra mundial. La vivísima relación de estos hechos se puede leer en De cómo llegué a saber que el coronel Redl era un espia, de Kisch.

Años después de estas actividades periodístico-detectivescas y de otras muchas, relacionadas por ejemplo con la prestidigitación, el tatuaje y el fútbol amateur, Kisch llegó a España. Vino, como tantos otros antifascistas del mundo, a ofrecer su solidario apoyo a la causa republicana. Su trabajo en El Mono Azul es fácil de documentar (Fig. 6).

La derrota de 1939 - hacen hoy seis décadas- y el comienzo de la segunda guerra mundial, significaron para Egon Erwin Kisch —antifascista y judío - una dramática agudización de la criminal amenaza que se cernía sobre su cabeza. Seis años antes, en 1933, víctima de la gran redada de opositores que ordenó Hitler al día siguiente del incendio del Reichstag, Kisch había estado prisionero en la temible cárcel de Berlín-Spandau. Sabía pues, muy bien, que si caía de nuevo en manos de la Gestapo no salvaría la vida por segunda vez. Por eso salió de Europa con destino a EEUU, donde le fue denegado el permiso de residencia; optó entonces por el asilo que le concedió México y marchó al exilio al país donde reencontraría a Pablo Neruda, para reiterarle allí la pregunta ¿por qué Neruda? Pero si Kisch pensaba que esta vez lograría conocer o descubrir la verdad, se equivocó; en Ciudad de México su pregunta también se quedó sin respuesta. $\mathrm{O}$, mejor dicho, la que obtuvo fue la que él mismo había ideado e insinuado al poeta: que ese nombre lo había tomado del de Jan Neruda. Pero esa respuesta, sabiéndola gestada a sugerencia propia y además - por haberlo comprobado personalmente- sabiendo que en España e Hispanoamérica ese escritor checo era prácticamente desconocido, le resultaba inaceptable. Es, sin embargo, posible que siempre haya habido un malentendido; porque lo que Pablo Neruda podía y debió decirle a Kisch, era únicamente lo que siempre dijo: que el nombre Neruda lo había encontrado casualmente en las páginas de una revista; que, en esa misteriosa revista, el poeta hubiese leído un cuento de Jan Neruda debió ser un agregado imaginado por el propio Kisch, que fue aceptado por muchos pero que él mismo se resistía a creer. De no haber sucedido esto último, el tema le habría servido magníficamente para uno de los reportajes que escribió en el país que le asiló, recopilados luego en su libro Descubrimientos en México. No pudo ser así y, años después, Kisch todavía se lamentaba de no saber toda la historia del nombre de Neruda. Su olfato de sabueso le hacía darse cuenta de que lo poco que él sabía acerca de ese enigmático caso, no era más que una mínima parte de la verdadera historia que «olía» tras ese nombre. Otra prueba de que con la respuesta que él mismo ayudó a prefabricar no podía dar por resuelto el caso, es que terminada la segunda guerra mundial $-\mathrm{y}$ por fin retornado a Praga - recibió allí la visita de Neruda; y al reencontrarse con él, le hizo por enésima vez la famosa pregunta. Neruda recuerda esa escena en Confieso que be vivido y también en la entrevista que, con ocasión del Nobel, le hizo L'Express de París en 1971. Cuenta que en Praga, Kisch llegó a apelar a su edad —era 
unos veinte años mayor que él- al pedirle que finalmente le revelara la verdad acerca de su nombre electivo (Fig. 7). Al periodista francés que le pregunta por qué cambió su nombre por el de Pablo Neruda, le responde: «hubo un gran poeta y periodista checo, Erwin Kisch, que pasó muchos años de su vida persiguiéndome y haciéndome la misma pregunta que usted, en Madrid, en México, en Praga. Y en Praga me dijo: «cuéntame el final de la historia..., ya estoy viejo y te he perseguido tanto tiempo...». En Confieso que be vivido, de manera parecida dice: «...nos habíamos conocido en España y como él manifestaba la insistente curiosidad de saber por qué motivo me llamaba yo Neruda sin haber nacido con ese apellido, yo le decía en broma: - gran Kisch, tú fuiste el descubridor del misterio del coronel Redl, pero nunca aclararás el misterio de mi nombre Neruda». Y así fue. Kisch moriría en Praga, en 1948, sin haber logrado saber por qué —en octubre del año 1920- el joven poeta chileno Neftalí Reyes se había rebautizado con un sonoro nombre checo. Porque Neruda, aunque nada de extraño sea a la índole del idioma español ni a sus hábitos onomásticos —como bien dice Loyola- es un nombre checo.

Lo dicho hasta aquí en relación al nombre de Neruda, era más o menos lo poco que quien les habla sabía, o creía saber, hasta hace algunos años. Y al parecer, todo se iría a quedar en eso. Pero al profesor Loyola se le ocurrió la excelente idea de publicar una antología de la poesía de Pablo Neruda, en cuidada edición de bolsillo ${ }^{1}$ y con una introducción que en parte se ocupaba, naturalmente, del nombre del poeta. Como si esto fuera poco, en dicha introducción Loyola puso una nota (la nota «2 bis») que tuvo la virtud de reactivar mi ya casi olvidado interés por intentar desentrañar el enigma del nombre elegido por Neftalí Reyes, famoso ex-alumno del Liceo de Temuco. Dice así: "Ya escritas estas notas, nos llega desde Chile la edición 187 de la revista Hoy (18 de febrero de1981) donde Miguel Arteche introduce la posibilidad de que el apellido Neruda haya sido tomado por el estudiante Neftalí Reyes, no directamente de alguna traducción de Jan Neruda, sino de la mención que Sherlock Holmes hace de un tal Norman Neruda, pianista, en el relato Study in Scarlet, de Conan Doyle, ya publicado en Chile bajo el título de
Un crimen extraño (Santiago, Lit. Universo, 1908). La observación nos parece bastante atendible, en especial considerando la temprana y nunca desmentida inclinación de Neruda hacia lecturas enigmáticas y policiales (Fantomas, en su infancia; Raymond Chandler y James Hadley Chase, en su madurez)».

Esta combinación Neruda-Holmes me dejó fascinado. Antiguo lector de las aventuras de Sherlock Holmes en los largos inviernos temuquenses de mi adolescencia, vi transformarse el enigma del nombre de Neruda en un caso quizá posible de resolver «aplicando los métodos» del muy célebre detective londinense; métodos, en este caso, quizá más efectivos que los de Kisch. Manos a la obra mi querido Watson, me dije (lamentablemente ni entonces ni ahora había un Watson; lo que se refleja, por ejemplo, en el tener que escribir -y hoy hablar- en primera persona). Lo primero que hice fue encargar el mencionado ejemplar de la revista Hoy. Esta tarea, aparentemente simple, demostró que, al ser una demanda transoceánica, podía adquirir caracteres de misión semiimposible. Al fin, después de mucho tiempo, conseguí una copia de la publicación (Fig. 8). Bajo el título "Sherlock Holmes admira a Neruda", y muy sonriente desde una fotografía, Miguel Arteche comienza en su artículo por hacer un resumen de la dogmática historia oficial del nombre, asombrándose, con toda razón, de que en la memoria de Neruda no hubiesen quedado huellas más claras y precisas de un suceso de tanta importancia como es el de la elección de un seudónimo que será definitivo. Luego aporta el dato de que la primera versión al castellano de los Cuentos de Malá Strana de Jan Neruda apareció el año 1923 y no antes. Comenta también el hecho de que Pablo Neruda nunca mencionara a dicho autor al hablar de sus lecturas de niñez y adolescencia. (Selena Millares, que investigó todo cuanto es posible saber sobre libros y lecturas de Neru$\mathrm{d} a$, tampoco encontró indicio alguno que sugiriese que el poeta se topó alguna vez, en
1

Madrid, Alianza Editorial, 1981.

Pablo Neruda, el enigma inaugural ENRIQUE ROBERTSON ÁLVAREZ 
su juventud, con algún libro de Jan Neruda). A continuación Miguel Arteche, refiriéndose al lugar de Jan Neruda en la entretanto dogmática respuesta a la pregunta ¿por qué Neruda?, dice: «esta es la versión ortodoxa del nacimiento de un poeta, y nadie, que yo sepa, la ha puesto en duda. Pablo dixit». A juzgar por lo que escribe Arteche y la inmediata reacción de Loyola, resulta evidente que existía una suerte de predisposición a considerar atendible otra versión del origen del nombre de Neruda que pudiese contraponerse a la versión ortodoxa. El artículo sigue así: «Sin embargo, la reciente relectura de un libro de Conan Doyle (Estudio en Escarlata. Pomaire, 1980), me hizo saltar de la cama y me planteó lo que en términos ajedrecísticos podría llamarse la variante herética de la Defensa Jan Neruda. En el capítulo cuarto de esta obra, Sherlock Holmes cita en dos ocasiones a una tal Norman Neruda: "Tenemos que darnos prisa - dice al doctor Watson-, porque deseo asistir al concierto del Halle para oír esta tarde a Norman Neruda». Más adelante: "Y ahora vamos a almorzar, y después a oír a Norman Neruda. La ejecución y el golpe de arco de esta mujer son maravillosos».

En 1908 aparece (Litografía Universo, Santiago de Chile) Un crimen extraño, es decir, con otro título, la misma novela. Entre 1902 y aquel año circulaban en Chile varios libros de Conan Doyle, aquellos cuyo héroe es el deliciosamente infalible y morfinómano Sherlock Holmes (Ramón Sopena, editor). Variante herética: ¿leyó Ricardo Neftalí Reyes, antes de 1920, este libro? Y si lo leyó -siempre dijo que era admirador frenético de las novelas policiales-, ¿pasó por alto ese apellido hermoso y extraño? Pero, ¿quién era Norman Neruda? Dice el Diccionario Enciclopédico Espasa-Calpe, 1957: «Neruda (Guillermina María Francisca). Concertista austríaca (1839-1911). Artista muy precoz, a los 7 años se presentó al público vienés. Los críticos afirman que no ha habido mujer que la igualara en su arte». Sin duda, y a pesar de ese nombre de pila -Norman-, producto tal vez de una confusión del novelista británico, se trata de la misma "virtuosa» (recordemos que la primera edición inglesa de Estudio en Escarlata se publica en 1888). Salazar Chapela sostiene una teoría algo más insólita: «Lady Halle, famosa violinista fallecida en 1911, adoptó el seudónimo de Neruda tomándolo del cuentista checo» (La Nación, marzo de 1954). Jan Neruda habría dado a luz a una gran (y precoz) violinista y a un gran (y precoz) poeta. No cabe mayor ni mejor fecundidad. ¿Surgió el seudónimo de la lectura de Estudio en escarlata? ¿Creó Pablo Neruda, más tarde, al citar a Jan Neruda, un mito de cultura? Si esto hizo, bien hecho estuvo, pues un poeta es creador de mitos, y estos son cosa mucho más seria de lo que la gente cree. Pero recordemos, en fin, la pregunta que Holmes lanza en otro libro ( $E$ l signo de los cuatro, Pomaire, 1980) al inefable doctor Watson: «¿Cuántas veces le tengo dicho que, una vez eliminado todo lo que es imposible, la verdad está en lo que queda, por improbable que parezca?».

Esta frase final, tan sherlockiana, me pareció estupenda como lema para dar una infalible base al seguimiento de "la pista Arteche» y de la «nota 2 bis» de Loyola. Esta última, al discrepar de la primera en un par de datos de importancia - cosa que vine a saber después porque, por las circunstancias ya relatadas, no las estudié en el orden de aparición sino a la inversa- me permitió estar ya muy preparado cuando al fin llegó a mis manos la copia de "Sherlock Holmes admira a Neruda" que tanto tardó en cruzar el Atlántico. Así fue que al arribar a mi escritorio "la pista Arteche», me encontró armado de fundamentales conocimientos, con los que me proponía eliminarle un par de datos imposibles. Y ver después, qué quedaba de ella. Pero me llevé una sorpresa al comprobar que los datos eliminables de partida no se encontraban en "la pista», sino en «la nota». La «nota 2 bis» - sin perder por ello nada de su decisivo papel en este asunto- atribuía sexo masculino al personaje «Norman Neruda» y lo transformaba en un eximio pero inexistente pianista a quien, sin duda alguna, Sherlock Holmes jamás tuvo el gusto de conocer ni admirar. En cambio, sí conoció y admiró a la Neruda o «Norman-Neruda», famosísima violinista de la segunda mitad del siglo XIX. Esto, y algo más, era lo que en mi sherlockiano papel de investigador, ya sabía yo al recibir y leer por fin el texto de «la pista Arteche» donde don Miguel había identificado correctamente a la violinista. La Norman Neruda del libro de Conan Doyle, es efectivamente la virtuosa Neruda del Espasa. El Espasa llama Guillermina a Mme. Neruda, que es nombre mucho 
más nerudiano que Wilma o Vilhelmine. Por eso, bajo la también nerudiana pregunta: ¿dónde estará la Guillermina?, centré en ella toda la investigación. Como veremos, este nombre salido de las páginas del Espasa me sirvió también para bautizar «Guillermina» a la prueba - contundente, espero- que mucho después pondría punto final a mi detectivesca encuesta.

Durante la larga espera del artículo de la revista Hoy, releí Estudio en escarlata y otras aventuras del famoso detective de la pipa y la lupa. Y...el violín. Porque también me sobró tiempo para leer algo de lo mucho que, acerca de la gran afición de Holmes al violín, han escrito los estudiosos sherlockianos de todo el mundo, que - dicho sea de paso- constituyen un numeroso y bien informado ejército de intrusos. Con tan valiosa ayuda, rápidamente logré reunir bastante más información acerca de Mme. Norman-Neruda que la que aportaba Arteche en su artículo, al que sometí a una disección destinada a eliminarle todos los imposibles que pudiese contener. Éstos fueron tres, de los cuales sólo uno es atribuible a su autor.

El primer imposible es un error de traducción e interpretación: donde en la versión en castellano - la de la Ed. Pomaire- de Estudio en escarlata Holmes dice «...deseo asistir al concierto del Halle...", se induce al lector a creer que «el Halle» es un teatro o una sala de conciertos. Pero en el original lo que Holmes dice es: «...I want to go to Hallés concert» (...deseo asistir al concierto de Hallé), donde Hallé es una persona, que en el Londres de entonces era tan real y existente como la virtuosa Norman-Neruda. A quien Holmes se refiere es a Charles Hallè, músico conocidísimo en el Imperio de su graciosa majestad la reina Victoria. Considerando que Hallè fue el segundo esposo de nuestra Guillermina, resumo algunos datos biográficos suyos: alemán de nacimiento, Karl Halle, eximio pianista, fue un virtuoso niño prodigio como lo fueron prácticamente todos los personajes que fui conociendo en el transcurso de esta lúdica investigación. De Alemania se trasladó a Francia; vivió doce años en París donde, además de afrancesar su nombre y apellido, conoció los primeros grandes éxitos de su carrera como pianista y director de orquesta. Se relacionó allí con músicos tan famosos como Berlioz, Chopin y Paganini. Padre de familia numerosa, se vio obligado a abandonar la capital francesa cuando la intranquilidad política paralizó durante un tiempo a la casi totalidad de las empresas de espectáculos artístico-musicales parisienses, lo que hizo casi imposible ganarse el sustento a muchos artistas. Así fue como en 1848, ampliadas sus actividades de músico con las de desempeñarse también como su propio agente y empresario, Charles Hallé cruzó el Canal de la Mancha y se estableció en Inglaterra, administrando y dirigiendo allí la «Hallè Orchestra» que él mismo fundó. En sus memorias relata los pormenores de su muy exitosa vida artística en las islas británicas: llegó a ser el primer director del Real Colegio de Música de Manchester y también de la Sociedad Coral Santa Cecilia, ejerciendo desde estos cargos una decisiva influencia que se mantiene hasta nuestros días. Así es como hoy la Orquesta de la ciudad de Manchester lleva su nombre, su biografía se puede leer en la Encyclopaedia Britannica y su retrato se puede admirar en The National Portrait Gallery de Londres. Como empresario de espectáculos musicales - $\mathrm{e}$ innato experto en relaciones públicas- el incansable Hallè se reveló igual de virtuoso. Reorganizó los tradicionales «Gentlemen's Concerts» de Manchester y se paseó por Londres y toda Inglaterra con sus no menos famosos "Monday's Popular Concerts", "Classical Chamber Music Concerts», y otros «Hallés Concerts» que deleitaban a Holmes y sus contemporáneos. En su orquesta siempre contó con los mejores violinistas y pianistas de la época. En el victoriano año de 1888 —año de aparición del libro Estudio en escarlata, primera aventura de Sherlock Holmes- Hallè fue nombrado caballero del Imperio británico. Sir Charles Hallè se casó ese mismo año con su primera violinista, la famosa Mme. Norman-Neruda, viuda del músico sueco Fredrik Vilhelm Ludvig Norman, más conocido como Ludwig Norman.

Al nombrar a este último, damos con el segundo imposible que eliminar de «la pista Arteche». Es aquél donde don Miguel comete el error de ver en Norman un nombre de pila, y atribuir dicho error a una presunta confusión de Conan Doyle. Lo cierto - y en esto no hay confusión alguna- es que Norman es el apellido de Ludwig Norman (1831-1885), director de la orquesta de Esto-
Pablo Neruda, el enigma inaugural ENRIQUE ROBERTSON ÁLVAREZ 


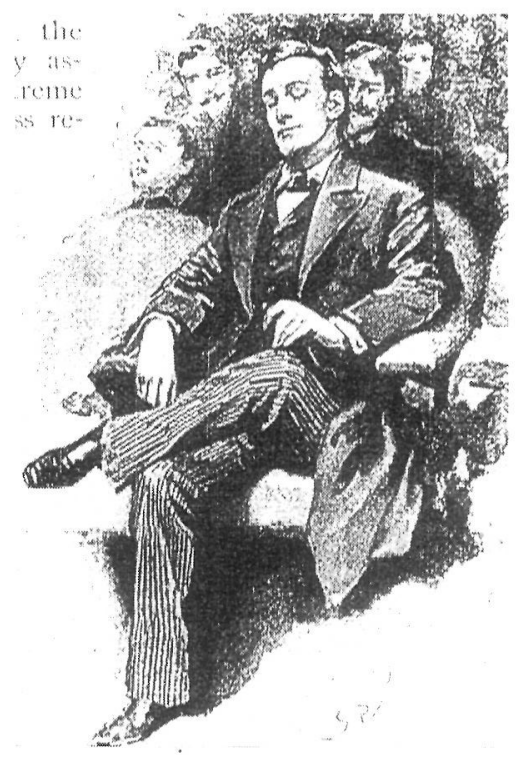

FIG. 9. Holmes escucha un concierto.

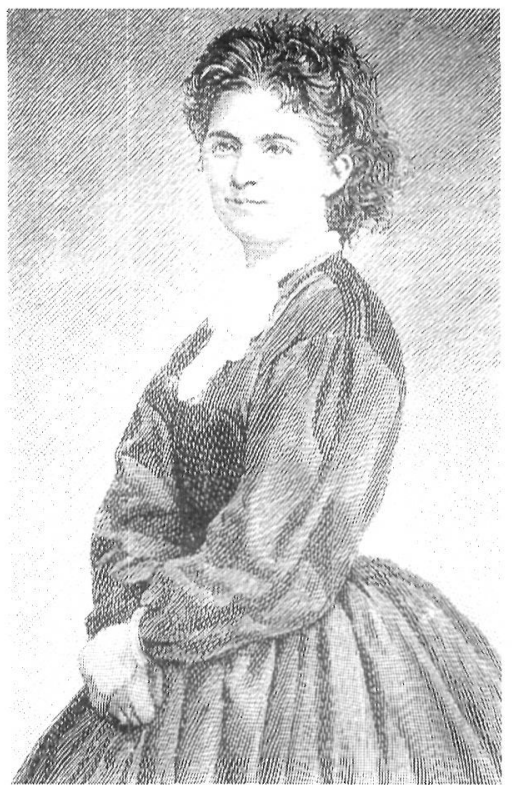

FIG. 10. Norman Neruda en un libro esencial sobre Holmes.

2

Barcelona, Lumen, 1989.

3

London, W.S. Baring-Gould, 1968. colmo, Suecia. Y, desde 1864, esposo de la virtuosa violinista Wilma Neruda. El matrimonio NormanNeruda se separó el año 1869. Sin embargo ella siguió llamándose oficialmente Mme. Norman-Neruda, hasta enviudar en 1885. Tres años más tarde, al contraer matrimonio con Sir Charles Hallè, nuestra Guillermina pasó a llamarse con toda propiedad, Lady Hallè. Sin que por eso, jamás se le ocurriese la idea de adoptar como seudónimo el nombre de un escritor checo, como sugirió Salazar Chapela, citado en la "pista Arteche». Con esto queda claro que el tercer e insólito imposible que eliminar de «la pista Arteche», es esa descabellada versión.

Con esta eliminación de imposibles, se acentuó mi confianza en los métodos de Holmes. Pero, conociendo mis limitaciones, me di a la búsqueda de algo que me ayudara a su aplicación y empleo más correcto. Así fue como di con un libro indispensable, que puedo recomendar a quien interese. Se trata de $E l$ signo de los tres de Umberto Eco y T. A. Sebeok (eds.) $)^{2}$ Me pareció especialmente interesante que la portada de este libro mostrase a Holmes sentado en la primera fila de un teatro, escuchando con absoluto deleite un estupendo concierto (Fig. 9); quizá uno de la orquesta de Charles Hallè con su magnífica violinista Mme. Norman-Neruda. El signo de los tres remite, claro, a $E l$ signo de los cuatro de Conan Doyle, pero sobre todo a temas tales como signo, objeto, interpretación; abducción, inducción y deducción; etc. De más está decir que no se puede esperar que la lectura de $E l$ signo de los tres lo transforme a uno en experto en abducción en grado limítrofe a la adivinación; pero permite ahondar algo en materia y hasta, con algún esfuerzo, permite imaginar a Holmes diciéndole a uno: «Ya conoce usted mis métodos». Chifladuras de uno. En cambio no se puede calificar de chifladura el afirmar que la lectura de otro muy recomendable libro: The annotated Sherlock Holmes ${ }^{3}$ puede llevarle a uno a dárselas de experto en la vida y milagros de «el sabueso londinense».

En The annotated, biblia de los sherlockianos, no podía faltar un destacado lugar para Mme. Norman-Neruda. La presentan allí, con retrato y todo (Fig. 10 ), reseñando brevemente las diversas etapas de su vida y comentando lo que sí parece una confusión de Conan Doyle que, en el brumoso Londres de Study in Scarlet, la hace interpretar a Chopin. La ayuda de The annotated y otros valiosos libros y revistas, me hizo posible conocer más detalles biográficos de «la Guillermina». Nació en Brünn el 21 de marzo de 1839. De su padre, el músico Josef Neruda, recibió las primeras lecciones de violín tan temprano y con tanto aprovechamiento que, a partir de los seis años de edad, en trío con sus hermanos Amalie, pianista, y Franz, violonchelista - también muy precoces intérpretes - comenzó a hacer giras artísticas por muchas ciudades de los imperios austro-húngaro y alemán. Praga, Viena, Leipzig, Berlín y Hamburgo, más o menos en ese orden, oyeron y aplaudieron a la niña prodigio. A los diez años de edad debutó con mucho éxito en Londres, ante la entusiasmada audiencia del Princess's Theatre. Después fue el público de París el que la colmó de elogios. Fue llamada: «el hada del violín», «la Paganini femenina», etc. Pero no sólo el público, también maestros como Joachim, Vieuxtemps, von Bülow y otros, reconociendo su asombroso talento y técnica, no dudando en calificarla como la violinista femenina más importante de su tiempo. Con Joachim, el mejor violinista de entonces, Wilma Neruda interpretó a Bach en la Philarmonie de Berlín; fueron unos extraordinarios conciertos para un dúo de fantásticos Stradivarius, pues ambos poseían un ejemplar de estos famosos violines. Por su parte Vieuxtemps, que sencillamente la consideraba la violinista ideal y alababa al mismo tiempo su femineidad, le dedicó muy especialmente su Sexto Concierto. A los veinticinco años de edad, Wilma Neruda - que ya tenía en su haber casi dos décadas de exitosa vida artística- contrajo matrimonio con Ludwig Norman, director de la orquesta de la Ópera de Estocolmo. Fueron cinco los años que Wilma vivió en la capital sueca. Durante ellos se desempeñó como profesora de violín de la Real Academia de Música Sueca, cargo que nos imaginamos 
rutinario y quizá tedioso para ella, a pesar del reconocimiento de que también gozaba allí. El rey de Suecia la condecoró y nombró Virtuosa de la Música de Cámara, que debe haber sido algo así como otorgarle el Nobel de la Música. De nada le valió esto al monarca sueco, admirador de nuestra Guillermina. Después de la obligada pausa de la maternidad -Wilma tuvo un hijo, que falleció trágicamente cuando era joven-, se apoderó de ella la inquietud de pensar que su carrera artística se congelaría irremediablemente en esas nórdicas latitudes. Residiendo aún en Estocolmo participó en algunos conciertos que se llevaron a efecto en Londres. El paso estaba dado. Se separó de Ludwig Norman y se estableció definitivamente en las brumosas márgenes del Támesis, a escasa distancia de un famoso domicilio: Baker Street 221-B. Esto último está dicho aquí intencionadamente, porque algunos indicios hacen pensar que Wilma era conocida de Holmes y Watson, desde antes de su casamiento con Norman y traslado a Estocolmo. Y que desde entonces había quedado grabada en los complicados archivos mentales del detective, como «la mujer»; único ser humano de sexo femenino que mereció su reconocimiento y admiración; lo que en el caso del gélido Holmes es mucho decir. Los indicios, si bien interpretados, hacen sospechar que Wilma Neruda sea el personaje real que está detrás de la inteligentísima Irene Adler, personaje de ficción que, en el relato Escándalo en Bobemia, se casa con Norton y se va de Inglaterra, dejando a Holmes derrotado y humillado, pero también prendado de ella. Si se pudiese confirmar la sospecha de que Wilma es quien se oculta tras Irene, cosa nada fácil a estas alturas, uno no podría resistir la tentación de querer identificar también al real personaje que se esconde tras el curioso heredero del trono de Bohemia, que, según el relato, vestía llamativos ropajes que recuerdan los hábitos indumentarios del entonces Príncipe de Gales. A falta de un Watson, habría que tener un amigo como el cerrajero y futbolista Wagner, que ayudó a Egon Erwin Kisch a destapar el secreto del coronel Riedl; sólo alguien así podría ayudarle a uno a descerrajar archivos que quizá encierren principescos y explosivos secretos británicos. Lamentablemente, o tal vez para mejor, no hay tal Wagner; porque si lo hubiese se podría intentar — con la ayuda de la tecnología gené- tica actual- aclarar si la paternidad del hijo de Wilma perteneció o no a su primer marido -Norman, que no Norton- del que se separó. Porque ese hijo perdió la vida en circunstancias un tanto extrañas. Accidentalmente, según se dijo. A lo peor se topa uno con un muy oscuro asunto. En fin, como se puede apreciar, esto de meterse a intrusear aplicando los métodos de Holmes, puede tener insospechadas implicaciones que traspasan el límite de los siglos, y otros también.

Una vez que a uno le asalta una sospecha que comprueba combinable con otra, se transforma en un redivivo «sabueso londinense». Aunque sea en la forma de un pálido y epigónico remedo, «un poco cómico y un poco venerable», como dice Borges. Del modo que sea, resulta compensador comprobar la razón que asiste a Borges en ese poema suyo en el que asegura que "pensar de tarde en tarde en Sherlock Holmes, es una buena costumbre que nos queda». Esa afirmación me obligó a releer ese poema y también Borges oral4. Se trata de la recopilación de los textos de cinco clases que hace unos veinte años dio Borges en la Universidad de Belgrano, Argentina. En la clase que tituló «El cuento policial»-que era la que me interesaba releer- encontré la frase que al mencionar expresamente a Neruda, establece el nexo - «el hilo invisible»- entre todos estos aparentemente dispares asuntos. Esto me devolvió la casi perdida coherencia, necesaria para reiniciar las investigaciones.

A partir de 1869, en Londres, la vida artística y privada de Mme. Norman-Neruda recuperó la actividad que tenía antes de su casamiento y traslado a Estocolmo. Moser, autor de Historia de la interpretación del violín, que conoció personalmente a Wilma cuando ésta regresó a las islas británicas, le dedica una serie de elogios que obligadamente tienen que llamar la atención de un sherlockiano; porque los formula con casi las mismas palabras que ya habíamos oído decir a Holmes en Estudio en escarlata: «her attack and her bowing are splendid», que se citan traducidas en la «pista Arteche» como «la ejecución y el golpe de arco de esta mujer, son maravillosos». A renglón seguido, Holmes - según testimonia Watson - formula la pregunta que despista mucho a los sherlockianos músicos: «¿Cómo se titula esa piececita de Chopin que ella interpreta tan
Pablo Neruda, el enigma inaugural ENRIQUE ROBERTSON ÁLVAREZ 


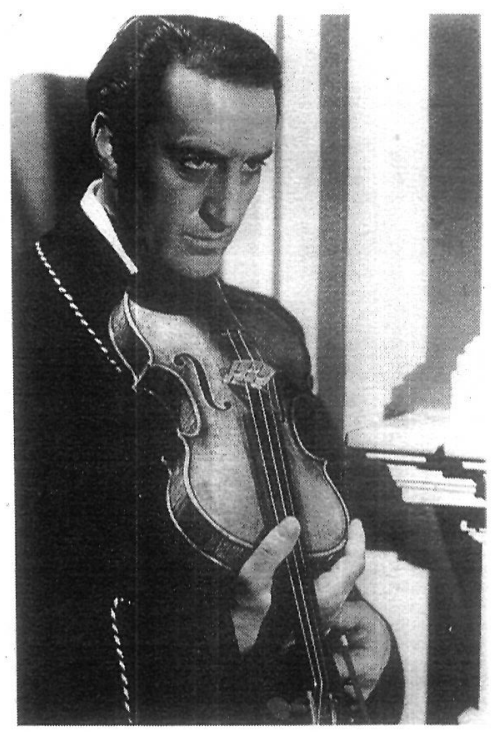

FIG. 11. Una figuración de Holmes tocando su Stradivarius.

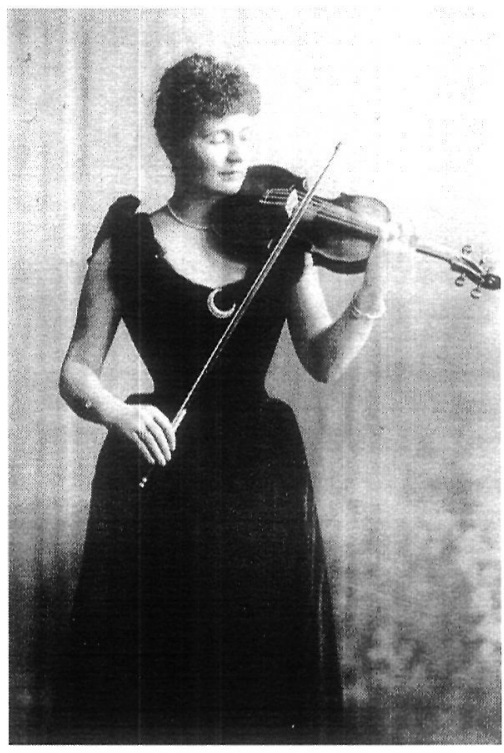

FIG. 12. Norman Neruda toca su Stradivarius. magnificamente?» ("What's that little thing of Chopin's she plays so magnificently?»). Desconcertante, si se sabe que Chopin nunca compuso «una piececita» para violín. Sea como fuese, el caso es que como solista o como miembro de un «ensemble», Wilma se constituyó durante décadas en la principal atracción de la vida musical de la ciudad del Támesis. Así lo documentan todas las fuentes que la nombran sola o unida al nombre del incansable Charles Hallé. Otras la mencionan en relación a la nobleza y a la familia real británica. El príncipe Alfred le expresó su gran admiración no sólo con elogios; le regaló un magnífico Stradivarius fechado en 1709, uno de los ejemplares más perfectos de la producción del famoso luthier de Cremona. Otra versión asegura que fue el Duque de Edimburgo y no el Príncipe Alfred quien regaló el Stradivarius a Wilma. Y complican la cosa asegurando que fue un regalo que el Duque le hizo a medias con los Condes de Dudley y Hardwicke. Esto parece un intento de echarle bruma del Támesis al asunto, para hacerlo perderse de vista en medio de una espesa neblina londinense. Hoy, gracias a las revistas del corazón, nos habríamos enterado hasta del último detalle del presunto «affaire» que se huele tras esto. Pero, tratándose de un asunto decimonónico, nos tendremos que conformar con lo que hay, que no es mucho. No sé quién será el actual propietario del Stradivarius de Wilma, pero hace un tiempo me pareció relevante para la investigación el averiguar qué había sucedido con ese violín después del fallecimiento de la virtuosa, acaecido en Berlín el año 1911. La idea para justificar esta búsqueda era la siguiente: tanto la noticia de la muerte de la famosa violinista Lady Hallé, como también la noticia de lo que había sucedido con su Stradivarius podrían haber aparecido en alguna revista.Y esta podría haber sido la leída por Neftalí Reyes en Temuco: si en la presunta noticia se aclaraba que el trío Lady Hallé, Mme. Neru- da y Norman-Neruda eran una misma persona, tendríamos allí el apellido Neruda que atrajo la atención de nuestro joven poeta temuquense. Tan extremadamente descabellada no debió ser esta idea porque, al fin, descubrí que el año 1913 un diario berlinés había publicado la noticia de que los hermanos Neruda, herederos de Lady Hallé, ponían en venta el bellísimo Stradivarius que había pertenecido a la virtuosa. Hasta ahora no sé quién lo compró, ni falta que hace. Puede que el comprador haya sido el propio Sherlock Holmes; aunque, según Watson, el detective violinista compró su Stradivarius mucho antes, por cincuenta y cinco chelines, en un negocio de compraventa de la Tottenham Court Road de Londres. (Fig. 11). En las aventuras de Holmes es posible encontrar cuatro personajes, tres de ellos reales, que poseen un Stradivarius. Holmes mismo y tres más: dos de ellos son Wilma y Paganini. Durante una breve estadía en Londres decidí abandonar esta línea de investigación. Esta pista era demasiado complicada y difícil para un investigador amateur. Además, el negocio de compraventa donde Holmes compraba violines usados ya no existe.

De todos modos y como se verá, después tuve obligadamente que ver con el otro violinista admirado por Holmes y poseedor de un Stradivarius. Antes de referirme a él y a riesgo de atosigarles, permítanme darles a conocer un par de detalles más de la historia de Lady Hallé. Siguiendo su huella, estuve también en Manchester, cuando allí se conmemoraba el centenario de la muerte de Sir Charles Hallé. Como ya he dicho, la orquesta de la ciudad se llama «Hallés Orchestra». El victoriano hotel en que me alojé estaba situado a escasa distancia de la sede de esta orquesta y, mejor aún, justo enfrente de la biblioteca de la ciudad. Allí, en una vitrina de la biblioteca, se exhibía el original de una hermosa fotografía de Lady Hallé. Seguramente fue tanto el interés que mostré, que amablemente la sacaron de la vitrina para permitirme hacer una copia de ella, lo que agradecí muchísimo. Hela aquí (Fig. 12). Además pude saber otras cosas interesantes acerca de Sir Charles y Lady Wilma que, según me dio la impresión, en esos días revivían en Manchester. Influenciado por el curso de mi investigación, viví una experiencia muy curiosa que me llevó a los salones del edificio que en la actualidad es el museo de 
pintura de la ciudad, cuyas mudas paredes se llenaron en su día de los ecos de los violines de Nicolo Paganini primero, y de Wilma Neruda después. El 25 de octubre de 1895, pocas semanas después de que Wilma y su esposo volvieran de una celebrada gira por Sudáfrica y Australia, Sir Charles Hallé, que entonces contaba con sanos y activos 76 años de edad, falleció bruscamente de una hemorragia cerebral. Las crónicas relatan que su deceso produjo gran consternación. Su viuda, veinte años menor que el difunto, recibió expresiones de condolencia procedentes de las más altas esferas. El príncipe de Gales - posteriormente Eduardo VII, rey de Inglaterra- presidió un comité, que integraban también los reyes de Suecia y Dinamarca, para ayudar a Wilma que al parecer heredó compromisos que financieramente la ponían en serias dificultades. El resultado de la acción de tantas testas coronadas estuvo a la altura de ellas. Se la ayudó económicamente y además, se le cedieron los títulos de propiedad de un palacete en Asolo, Italia. Un tanto apresuradamente quizá, Wilma se trasladó a residir a Italia en compañía de su único hijo, dejando el país en el que había vivido tantos años. Esta decisión suya tuvo lamentables e imprevisibles consecuencias. Allí falleció su hijo, en un trágico accidente. Wilma trasladó nuevamente su domicilio. Esta vez -en 1899- se estableció en Berlín, reanudando sus actividades profesionales como concertista, trabajando además como profesora en el Conservatorio de la capital alemana. Sin embargo, cada año volvió a Inglaterra a participar en algún concierto. En 1901, la reina Alexandra la nombró Violinista de Palacio. En enero de 1908 Wilma hizo su última aparición ante el público de Londres, participando en un concierto en memoria de su amigo el violinista Joseph Joachim fallecido pocos meses antes. Ella a su vez, la famosa violinista Wilma Maria Franzisca Neruda, Lady Hallé, la Norman-Neruda de Estudio en Escarlata, nuestra Guillermina, falleció en Berlín el 15 de abril de 1911 a los 72 años de edad. Una de sus últimas actividades profesionales en Berlín —esto se menciona muy rara vez-fue la de acompañar con su violín, al jovencísimo y virtuoso cellista catalán Pablo Casals.

A todo esto, mucha investigación, mucho dato biográfico y mucha anécdota. Pero, a resultas de todo, lo único que podía oponer a la «variante herética» de Arteche era poder afirmar rotundamente que el nombre de la violinista NormanNeruda — tanto en vida de la artista como en los años siguientes a su fallecimiento- no sólo aparece en Estudio en Escarlata si no que, en sus tres variaciones, se lo puede encontrar en no pocos diarios y revistas europeas. Es importante señalar esto, porque la existencia de dichas revistas descalifica cualquier desmentido que se le quiera hacer a Neruda. Es, en efecto, perfectamente posible que encontrase su nombre en una de ellas, como siempre afirmó. El nombre Neruda de Wilma, claro, no el del escritor Jan Neruda. Con esto se podría haber

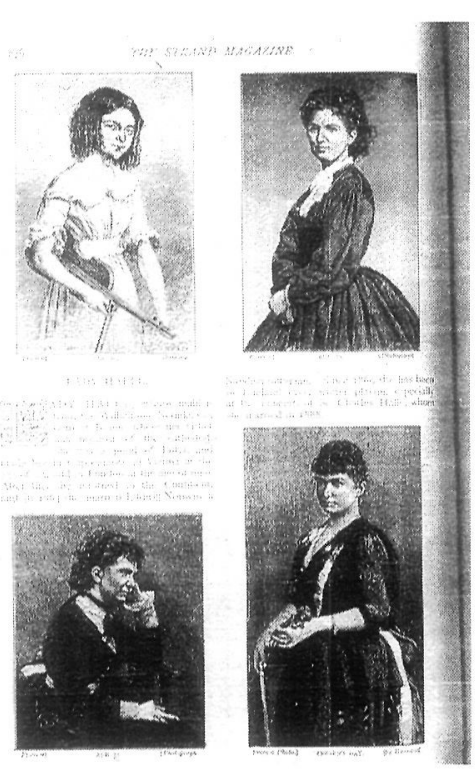

FIG. 13. Norman Neruda en una revista de 1892. dado por terminada la investigación. Pero una adquirida intuición sherlockiana me hacía notarle un sabor un tanto descafeinado a la cosa, si la dejaba hasta ahí. No porque no pudiese demostrar la existencia de tales revistas. Para esto nada mejor que mostrar, por ejemplo, el ejemplar de septiembre de 1892 (pág. 276) de la revista ilustrada mensual The Strand Magazine (Fig. 13) de Londres, revista hermosa e interesante, impresa en papel de excelente calidad. No debió ser extraño hallarla entre los libros de una buena biblioteca particular. Su formato se prestaba para ello y además se la podía adquirir encuadernada en tomos de seis ejemplares, como lo hice yo mismo en un anticuario. En Temuco, quizá en la biblioteca de Carlos Masson, podría haber habido alguno de esos tomos, o ejemplares sueltos. No importaba cuán viejos fuesen, cada ejemplar de esa revista se mantenía largo tiempo vigente por sus historias, anécdotas, etc. Conan Doyle publicó en ella las Aventuras de Sherlock Holmes y otras obras suyas, todas estupendamente ilustradas. En Temuco, que contaba no sólo con habitantes de habla inglesa sino también con una iglesia anglicana y un colegio inglés, no debió haber sido imposible encontrar un ejemplar de The Strand Magazine, una de las más atractivas revistas inglesas de su tiempo. Cabe pues dentro de lo posible que Neftalí Reyes encontrase ese ejemplar de septiembre de 1892, con toda una página ilustrada dedicada a Wilma Neruda, Lady Hallé. Y si no fue The Strand Magazine la revista hojeada
Pablo Neruda, el enigma inaugural ENRIQUE ROBERTSON ÁLVAREZ 


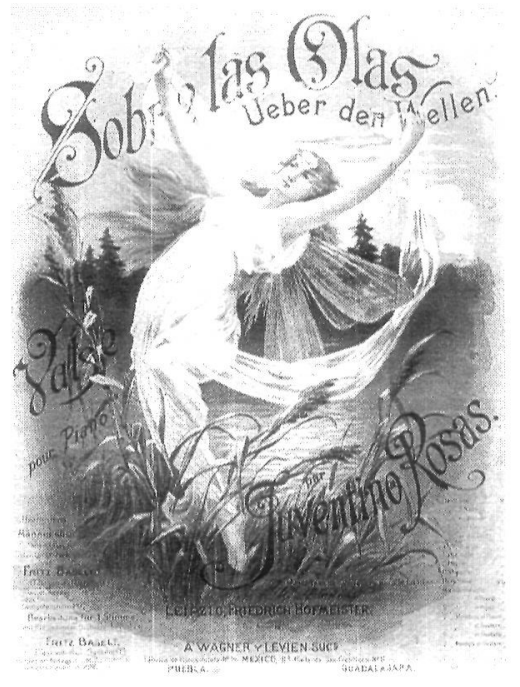

FIG. 14. Partitura del «Vals sobre las olas».

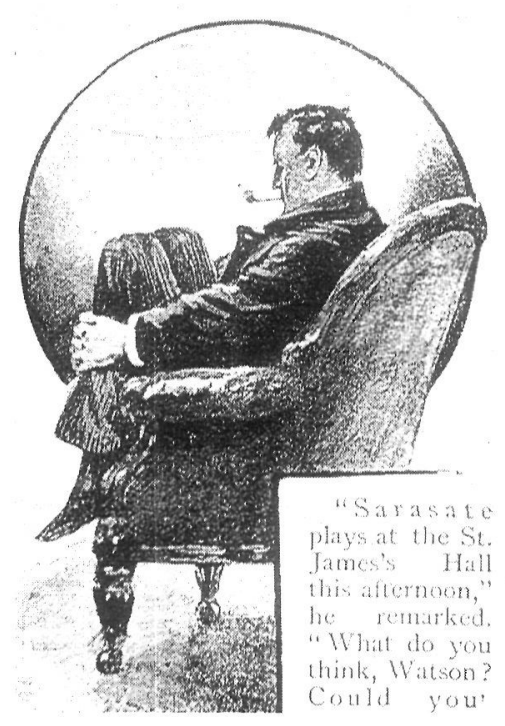

FIG. 15. Holmes en La liga de los pelirrojos: "Sarasate toca esta tarde en San James Hall». casualmente por Neftalí, pudo haber sido otra. Por ejemplo la revista Dalibor, que en la página 251 (Vol. XXXIII-1911) publicó unas palabras de despedida que tituló «Obituary for Wilma Neruda». Pero el éxito de la investigación destinada a documentar la declaración del poeta - probando, así, que es perfectamente posible que hubiese encontrado su nombre en una revista - no me liberó de la sensación -quizá similar a la que sintió Egon Erwin Kisch- de que algo seguía faltando en esta historia, un detalle que no acertaba a identificar. Dicho sea de paso, Kisch debió haber conocido la revista Dalibor en Praga, pero en su monomanía de pensar sólo en Jan Neruda, no pensó en que la Guillermina también se apellidaba Neruda. Craso error. En ella estaba la clave. En fin, repito que sentí que todavía faltaba algo. Pero, carente de ideas, me ví obligado a hacer una pausa en la investigación. No sé cuánto duró. En ese intervalo, sin alejarme de la música, me dediqué —en compañía de un amigo mío al que también le chiflan estas cosas - a estudiar a Neruda en relación al «Vals sobre las Olas». En casa de este amigo - hijo del querido periodista chileno Alfredo Olivares, que fue quien me hizo posible la obtención de la fotocopia de «la pista Arteche»- vimos un interesante vídeo acerca de Isla Negra, que le había enviado su padre. En una escena de dicho vídeo, se veía un artilugio giratorio y antediluviano - previo a las victrolas- del que salían los compases del Vals sobre las Olas. Debía, sin duda, tratarse de la primera versión mecánicamente reproducible del famoso y pegajoso vals. Nos imaginamos al poeta hipnotizado ante ese raro aparato que echaba al aire las notas que le habían fascinado desde niño, como recuerda en las primeras páginas de Confieso que be vivido. No sólo releímos esas páginas, sino que también declamamos solemnemente la "Oda al Vals sobre las Olas", brindando por su autor, que también se acordó de ese vals -y lo hizo interpretar al violín- cuan- do comía en Hungría junto a su hermano Miguel Ángel Asturias. Después —con nuestras respectivas esposas, claro- danzamos nerudianamente el viejo vals. Al día siguiente -tengo testigos- en un mercado callejero, entre un montón de revistas viejas, encontré un ejemplar de la centenaria partitura del "Vals sobre las Olas», una primera edición expresamente hecha para América lujosamente litografiada a todo color (Fig. 14). El autor del famoso vals que le hizo seria competencia a los mejores valses de Viena, fue el mexicano —niño prodigio también- Juventino Rosas. En su breve vida, Rosas jamás visitó el viejo continente. En cambio su vals, «El Vals sobre las olas», se paseó por todos los salones de Europa no faltando quien atribuyese su autoría a Strauss. Para qué decir que interpretamos el hallazgo de esta partitura como un raro mensaje del poeta. Quisimos hacer un vídeo, escribir algo; al final no pasó nada. Aunque, claro, todavía podría pasar. Si cuento el apretado resumen de todo esto - que es otra historia- es porque de manera tangencial tuvo algo que ver con lo que pasó después, cuando al fin se dio la coyuntura para retomar el asunto de la Guillermina.

Un día, revisando notas, me di cuenta de que había dejado un cabo suelto. Era el relacionado con el tercer personaje no ficticio $-\mathrm{y}$ dueño de un Stradivarius - del que habla Holmes en uno de sus diálogos con Watson. Al escribir mis primeras notas sobre Holmes y el violín, llamé Melitón al tercer personaje; y lo archivé bajo ese nombre, con lo que sin querer yo mismo lo saqué del punto de mira de mis investigaciones. Grave error. Porque Melitón fue otro de los violinistas predilectos del detective de Baker Street. En La Liga de los Pelirrojos, Sherlock Holmes informa a Watson: «Sarasate plays at the St. James's Hall this afternoon» (Fig. 15). Lo dice con la absoluta certeza de estar hablando de alguien muy conocido. Y con toda razón porque, según el citado relato, en aquella brumosa tarde londinense, ofrecía uno de sus magníficos conciertos don Martín Melitón Sarasate y Navascués, navarro nacido en Pamplona el 10 de marzo de 1844 que, bajo el nombre de Pablo Sarasate -o Pablo de Sarasate- adquirió mucha fama y riqueza como violinista y compositor. Pablo Sarasate dio su primer concierto en Londres el año 1861, en el Crystal Palace, pero a partir de ese mismo año sus conciertos 
siempre se llevaron a efecto en la Sala que se llamó St. James's Hall a la que Holmes se refiere en la novela. Esta sala ya no existe en Londres; fue demolida en 1905 y en su lugar se construyó el Piccadilly Hotel.

El no haberme preocupado mucho antes de Sarasate me dejó, en mi papel de aprendiz de Sherlock Holmes, muy avergonzado. Porque Pablo Sarasate no se llamaba Pablo: ¡eligió llamarse así! Está documentado que fue bautizado con los nombres de Martín Melitón y que su fe de bautismo fue corregi$\mathrm{da}$ en el año 1878, cuando el violinista de Pamplona ya había cumplido 34 años de edad. (Fig. 16). Por este extraordinario hecho -haberse autobautizado Pablo, tal como lo hizo Neftalí Reyes- debí haber sometido a Sarasate, desde la partida, a una muy rigurosa investigación. Habría sido lo lógico, lo elemental, según Holmes. Sin embargo, como un Lestrade cualquiera, no lo había hecho. ¿Por arte de qué, Martín Melitón se había hecho llamar Pablo? Por arte de música, se podría decir; en analogía a lo que dejó dicho Ricardo Eliecer Neftalí: «mi nombre es Pablo por arte de palabra». Esto no podía significar otra cosa más que Neftalí no sólo leyó la palabra Neruda en una revista; también tenía que haber leído la palabra Pablo. Este pensamiento me hizo acometer con entusiasmo la tardía tarea de intentar atar el cabo suelto de la «pista Melitón». Pero lo único que se me ocurrió fue la ingenua idea de pensar que quizá, en alguna otra de las aventuras de Holmes y Watson, los nombres de Wilma Neruda y de Pablo Sarasate hubiesen sido mencionados juntos. Idea que los sherlockianos del The annotated se encargaron de hacerme desechar rápidamente: Holmes no vuelve a mencionar a estos violinistas en ninguna otra aventura. Ni juntos ni separados. De todos modos, dos cosas de mucho interés habían surgido de esto: la primera, haberme enterado del curiosísimo hecho de que el violinista Martín Melitón Sarasate, de la misma manera que el joven poeta Ricardo Eliecer Neftalí Reyes, había cambiado sus bautismales y pesados nombres de pila por el sencillo y apostólico Pablo.

El caso de Pablo Picasso es diferente. En la pila bautismal, Picasso se llamó Pablo Diego José Francisco de Paula Juan Nepomuceno María de los Remedios Cipriano de la Santísima Trinidad Ruiz Picasso. Una orgía bautis- mal. El pintor fue drástico; lo único que no se borró fue el nombre Pablo y el apellido materno. Es decir, a diferencia de Neruda y de Sarasate, no le fue necesario buscar su nombre Pablo en revistas o libros, estaba ya en la fe de bautismo que le tocó en suerte.

El segundo hecho, al que también atribuí mucha importancia, fue a la germinación de la idea de que los nombres de Pablo Sarasate y de Wilma Neruda pudiesen ser encontrados impresos, el uno junto al otro, si no en una novela de Sherlock Holmes por lo menos en otra parte. Por ejemplo en un artículo que tratase de los grandes violinistas del siglo XIX. Pero, si se les enumeraba en orden alfabético, ambos nombres estarían separados por lo menos por el de Paganini. A propósito de este último, Sherlock Holmes también admiraba mucho a Niccolo Paganini y sabía muchísimas cosas acerca de él. Lo atestigua Watson al decir: «(Holmes) me contó muchas anécdotas acerca de ese hombre (Paganini) extraordinario» («...he (Holmes) told. me anecdote after anecdote of that extraordinary man (Paganini)»). Seguramente, como de tantos otros temas, los conocimientos de Holmes sobre Paganini y su Stradivarius eran asombrosos; Holmes, ya lo dije, también era propietario de un Stradivarius. Esto me hizo elucubrar que otra posible lista de famosos violinistas del siglo XIX, sería la que incluyese sólo a los poseedores - no ficticios - de uno de estos extraordinarios violines. Sería una lista breve que permitiría fijarse mejor en cada uno de los enumerados. Sobre todo si el presunto artículo hubiese sido ilustrado con sendas fotografías, en cuyo caso sería obligatorio - dado que esas fotografías existenque una de ellas, la de Wilma Norman-Neruda se hubiese podido ver junto a otra, la de Pablo Sarasate, cada cual con su propio Stradivarius en las manos. Una revista así podría haber sido casualmente hojeada por Neftalî Reyes. Éste -que en ese preciso momento buscaba un seudónimo- habría elegido, al pie de la fotografía de Pablo Sarasate, el nombre Pablo; y, al pie de la de Mme. NormanNeruda, se habría prendado del apellido de Wilma, la Guillermina. Todo claro. Pero no
Pablo Neruda, el enigma inaugural ENRIQUE ROBERTSON ÁLVAREZ 
encontré dicha revista y seguir buscándola, con la cada vez más débil convicción de que realmente hubiese existido y pudiera encontrarla, se me fue haciendo cada vez más difícil. Por eso, fui dejando de lado esta búsqueda y orientando mi estudio a la vida y obra de los violinistas Sarasate y Paganini que, a diferencia de Wilma, no sólo eran intérpretes si no también compositores. Me aficioné a escuchar sus obras, interpretadas por violinistas contemporáneos. A Anne-Sophie Mutter, por ejemplo, la oí interpretando a Sarasate, mientras me imaginaba estar escuchando a Wilma, otra chifladura. Además me procuré un par de biografías de Paganini y quedé tan asombrado como Watson, de la vida y milagros de ese hombre extraordinario. Una anécdota muy curiosa, que aparece en una de las biografías (la de John Sugden), es la que relaciona a Paganini con Conan Doyle, pero no por medio de Holmes si no que «por Medium» de otro personaje. Me explico: la mayor chifladura de Sir Arthur Conan Doyle consistía en creer a pies juntillas en el espiritismo. Florizel von Reuter también, o al menos así lo aseguraba. Florizel von Reuter fue violinista; y no de los peores, según se dice. También él fue un niño prodigio. A alguien se le ocurrió llamarle «el Paganini redivivus». Puede que esta denominación haya dado la brillante idea a Florizel quien, ya mayorcito, empezó a asegurar que tenía comunicación directa con el espíritu de Paganini. Y que era el espíritu de éste el que, magistralmente, guiaba su mano de artista cuando tocaba el violín. Florizel, guiado quizá por motivos más pecuniarios que espirituales, escribió un libro sobre este espiritístico asunto (Psychical Experiences of a Musician) y consiguió que Conan Doyle le escribiera la Introducción, con lo que de partida pudo asegurar la venta de su libro al crédulo público del año 1928. Cosas de los espíritus, pensó uno escépticamente. Pero poco después, en una librería de viejo que acostumbro visitar cada dos o tres meses, dentro de un librito sobre Paganini encontré una carta firmada de puño y letra por Florizel von Reuter..., que no tenía nada que ver con el espiritismo, faltaría más. En todo caso me empezó a llamar la atención esta verdadera acumulación de casualidades. Debo reconocer que este hecho llegó a ponerme algo nervioso. Lo habitual, dicen, es que uno, en su cotidiana normalidad, asuma tales casualida- des o coincidencias simplemente como cosas raras que nos pasan. Y que, antes de olvidarlas o archivarlas en la memoria de las anécdotas, al no encontrarles explicación razonable, se diga a sí mismo: ¡qué extraño! o ¡qué curioso! Nada más. Otra cosa es que el asunto quede dando vueltas en la cabeza; esto tiene sus riesgos, puede revenir el seso. $Y$ fue en relación con esto último - memoria y sesos revenidos- que en mi búsqueda de datos acerca de Paganini recordé que muchos años atrás, en Temuco, había visto una película basada en la legendaria vida de este violinista. Después de mucho buscar di con una breve documentación acerca de este film titulado: Paganini (The magic Bow). Filmada en la posguerra, lo único que valía la pena de esa película inglesa era la música. Sonaba estupendamente; no es raro esto porque la interpretó el genial Yehudi Menuhin. La película, una mezcla de aventuras de El Zorro, Scaramouche y D'Artagnan, con Steward Granger en el papel de Paganini, era malísima; y al parecer su intención era convencer al público de que Paganini había sido un espadachín que tocaba el violín en sus horas libres. En sus memorias, el recientemente fallecido Yehudi Menuhin recuerda la historia de este film; dice: era tan malo que, durante la filmación, las más de las veces no sabía si reir a carcajadas o llorar a mares. Como se puede apreciar, acerca de Paganini se puede encontrar de todo, bueno y malo, desde el más allá hasta el séptimo arte.

Mucho más difícil es la tarea si se trata de Sarasate, porque acerca de él, en todas las enciclopedias y libros se repite más o menos lo mismo. Pero, una vez más, las casualidades afortunadas iban a estar de mi parte. Bajaba yo por las Ramblas de Barcelona cuando, en la vitrina de una tienda de música que está justo enfrente de la fuente de Canaletas, veo un libro que, según me habían dicho, no existía: Pablo Sarasate, biografía. La escribió Luis Iberni y estaba prácticamente recién salida de la prensa (1994). Tuve que encargarle a un amigo, el pintor chileno Víctor Ramirez, que me comprara un ejemplar un par de días más tarde porque la tienda estaba cerrada; y yo tenía que volver a Alemania. Al fin, una larga semana después, con el libro en las manos, me enteré de que se había celebrado el año del sesquicentenario del nacimiento del virtuoso violinista que se hizo llamar 
Pablo, aunque se llamaba Martín Melitón. La efeméride había motivado y hecho posible la edición de su biografía ilustrada. En ella pude encontrar a «la Guillermina» Neruda en el apartado en que se catalogan la obras que compuso Sarasate. Se documentaba aquí, que el año 1878, el prodigioso año 1878, Pablo Sarasate compuso «Romanza andaluza y Jota navarra, Op.22. Dedicadas a Norman Neruda». No sé lo que esto pueda significar, pero fue también en 1878 - lo dije anteriormentecuando la partida de nacimiento de Martín Melitón Sarasate fue corregida agregándosele, de primer nombre, Pablo. Coincidencias, casualidades; no hay motivos para pensar demasiado en ellas. Se consignaba además que la partitura fue editada en Berlín, por Simrock. Habiendo visto ya algunas antiguas partituras con dedicatoria, supe en ese instante que había saltado la liebre. Esta vez la cosa tenía sabor. La pista seguida — con sus tantas ramificaciones - había finalmente desembocado en una recta, al témino de la cual se divisaba claramente la meta. Me dí cuenta de que la tarea era encontrar un ejemplar de esa partitura editada por Simrock de Berlín. En su primera edición, claro, porque lo habitual es que ediciones posteriores ignoren las dedicatorias que ostentó la primera. No se trataba de una tarea fácil, no en vano habían pasado más de cien años y sucedido un par de hecatombes desde su edición. Basándome en el conocimiento de otras que debían parecérsele, pude hacer una descripción bastante aceptable de la partitura buscada y la envié a varias direcciones de las que me prometía éxito seguro. Estas direcciones no incluían ninguna de Pamplona, porque a partir de entonces ya no quería que el juego terminase muy pronto. En el Museo de la Música de Barcelona me habían informado de que todo el inventario del Museo Sarasate de Pamplona había pasado a manos de la Biblioteca de dicha ciudad; si quería conseguir una copia de la partitura que buscaba, me aconsejaban dirigirme a dicha biblioteca. Lo hice una vez, lo intenté por teléfono. Pero parece que no logré explicar mis intenciones. Además ya había decidido que no me interesaba una copia. Quería tener un original de esa partitura, tenía que ser posible encontrarla. De las mencionadas direcciones sólo una me contestó enviándome una partitura. No era precisamente la que buscaba, pero me ale- gró recibirla. Era de la época y estaba dedicada; es decir, en su portada se podía leer una dedicatoria impresa indicando que el autor ofrendaba su obra a una persona determinada. El librero remitente de esa única partitura que me llegó, leyó sobre ella el nombre Neruda y me la envió. Se trataba de una obra de Franz Neruda, hermano de Wilma. (Fig. 17). Tenerla en mis manos me hizo sentir un poco más cercano a la meta. Seguí rastreando febrilmente la que Sarasate, don Pablo, dedicó a Neruda, doña Guillermina. Nombré también «Guillermina» a esa partitura y la busqué en numerosas ciudades: Berlín, Viena, otra vez Manchester, etc. etc. A veces (en Bredevoort, Holanda, por ejemplo) pasé horas revisando centenares de partituras. En Bredevoort hay una librería de viejo al lado de la otra, en todo el pueblo. Pero nada; pasó más de un año y no pasó nada más. Comenzé a pensar que el hado de los hechos fortuitos, coincidencias y casualidades, se había cansado del juego. Abandoné el oneroso turismo de la búsqueda; había encontrado muchas cosas pero no esa partitura. Me comenzó a tentar la idea de que con la información que tenía reunida, podía ya escribir algo. Pero de nuevo, la sensación de que todo se descafeinaría si no mostraba lo principal, la partitura, me hizo desecharla. Porque esa partitura tenía que ser la «revista» de la que hablaba Neruda. Mirando viejas partituras, como la del «Vals sobre las Olas» o la de la obra de Franz Neruda y muchas otras, había llegado a esa conclusión. Y cuanto más lo pensaba, tanto más seguro estaba de su coherencia; tanto, que ya no me cabían dudas: así debió haber sido. Porque al echarle una despreocupada mirada a la portada de una partitura, me refiero a una de aquellos tiempos, nada tiene de raro pensar que se trata de una revista. Tanto el formato como la ilustración de la tapa pueden fácilmente inducir a ese error a cualquier persona que no se detenga a hojearla. Y esto último no es requisito para echarle una mirada a la portada. Y fijarse en los nombres impresos allí con grandes letras. Pablo Sarasate y Norman Neruda, por ejemplo. Eso es lo que debió haber sucedido el año 1920, cuando el joven
Pablo Neruda, el enigma inaugural ENRIQUE ROBERTSON ÁLVAREZ 


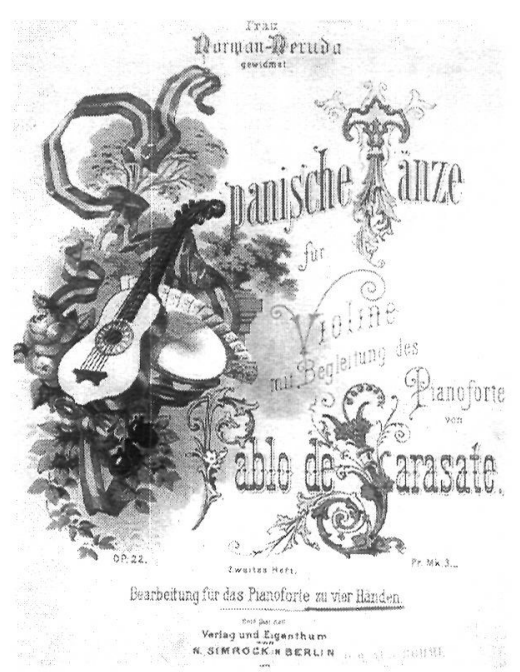

FIG. 18. Partitura de Pablo Sarasate dedicada a Norman Neruda en 1879 (Se reproduce en color en contraportada).
Neftalí Reyes leyó esos nombres «en una revista», en la portada de una partitura que le pareció una revista.

Alguien podría decir: "pero...¿ es posible sostener que en el fronterizo Temuco de los años 20 se podía encontrar una partitura de ese tipo?». La respuesta es sí, sin duda alguna. En la pujante ciudad que crecía a grandes pasos aún no había un Conservatorio de Música, se fundó pocos años después. Pero no por eso era raro disfrutar allí de un concierto de música clásica. La mejor prueba de esta afirmación la proporciona el propio Neftalí Reyes. En su Cuaderno de Temuco, en poemas fechados en el mes de diciembre de 1919, hay unos versos que hablan de violines y «del alma de Chopin brumoso». Están escritos pocos meses antes de que a Neftalí Reyes se le ocurriera llamarse Pablo Neruda. Estos versos permiten afirmar, sin temor a equivocarse, que en esas fechas, en Temuco, se llevaban a efecto selectas veladas musicales. Lo que, por lo demás, es conocido. Guardando las proporciones, se trataba de algo similar a los "Populars Concerts» de Charles Hallè y Wilma Neruda. Para llevarlos a efecto era, entre otras cosas, necesario tener partituras. Pensé que, por una de esas raras casualidades ya tan habituales, había sido el mismo Pablo Neruda el que me había hecho plantear la hipótesis de la partitura como revista. Porque tal como Paganini había guiado la mano de Florizel, Neruda había guiado la mía para dar con la partitura del «Vals sobre las Olas» en medio de un montón de revistas viejas. Metida entre ellas, a primera vista, esa partitura me había parecido una revista más, no había gran diferencia. Pero lo que había encontrado era una partitura. ¿Habría sido éste un fenómeno espiritista, como los que chiflaban a Conan Doyle, padre literario de Sherlock Holmes?

Como pasaba el tiempo y no conseguía dar con la partitura que buscaba, decidí conceder crédito a esta nueva chifladura. Total, una más entre tantas. Invoqué a Wilma con todo respeto. Y parodiando un poco a Egon Erwin Kisch - a quién también invoqué para que me ayudara- le dije solemnemente: «Wilma, te he perseguido a ti y a esa partitura durante tanto tiempo; dime por fin donde encontrar a la Guillermina». Y claro, no podía ser de otro modo, al día siguiente o subsiguiente, allí, en la misma librería de viejo a la que voy cada dos o tres meses la encontré en medio de otras partituras y revistas. Fue para mí un hallazgo nada exento de emoción y taquicardia. Aunque según Neruda, a Neftalí Reyes el fenomenal hecho le había parecido carente de todo encanto y maravilla. El creyó, claro, que veía una revista. Era una partitura. Juzguen ustedes: ¡aquí está! (Fig. 18). Una mirada a su portada permite al distraído lector —de igual modo que en su día le sucedió a Neftalí Reyes- apreciar que sobre ella es posible leer Pablo y también Neruda.

¡Elemental, queridos nerudistas!

Quizá esto demuestre cuán ciertas son las primeras palabras de Neruda en Estravagario: «Para subir al cielo se necesitan dos alas, un violín...»

Gracias por vuestra amable atención. 